\title{
Prevalence and factors associated with dental caries among children and adults in selected districts in Uganda
}

\author{
Annet Kutesa, Arabat Kasangaki, Moses Nkamba, Louis Muwazi, Isaac Okullo, Charles Mugisha Rwenyonyi
}

Department of Dentistry, School of Health Sciences, College of Health Sciences, Makerere University, Kampala

\begin{abstract}
Objective: The aim was to determine the prevalence and factors associated with dental caries among adults and children in seven districts of Uganda.

Methods: Participants aged 11-13 $(\mathrm{n}=1230)$ and 35-44 years $(\mathrm{n}=648)$ were randomly selected from urban and rural areas of Gulu, Soroti, Jinja, Masaka, Kabale, Kabarole and Hoima districts. They were examined by 4 trained and calibrated dentists for dental caries using Decayed, Missing and Filled teeth index as described by World Health Organisation.

Results: Overall mean DMFT score was 0.73 for children and 4.71 for adults. Generally, there was a higher mean DMFT score in the rural (2.19) compared to urban areas (1.97). In all the districts, except Hoima, there was a higher mean DMFT score of children in rural compared to urban. In adults, similar trend was mainly registered in Masaka, Hoima and Gulu districts. Most participants $(79.9 \%, \mathrm{n}=1309)$ occasionally ate sugared snacks. Overall, $95 \%(\mathrm{n}=1795)$ of the participants cleaned their teeth with plastic tooth brushes $(71.7 \%)$ and chewing sticks $(8.3 \%)$.

Conclusion: Although the severity of dental caries was low, the disease was widespread in the study population. A high proportion of participants reported consumption of sugared snacks and drinks, which calls for oral health education.

Keywords: Dental caries prevalence, severity, sugared snacks, tooth brushing, Uganda

DOI: http://dx.doi.org/10.4314/ahs.v15i4.33

Cite as: Kutesa A, Kasangaki A, Nkamba M, Muwazi L, Okullo I, Rwenyonyi CM. Prevalence and factors associated with dental caries among children and adults in selected districts in Uganda. Afri Health Sci. 2015;15(4):1302-7. http:/ / dx.doi.org/10.4314/abs.v15i4.33
\end{abstract}

\section{Introduction}

A decade ago, World Health Organisation (WHO) ${ }^{1}$ published a review of global oral health status, which emphasized that despite great improvements in oral health in several countries, problems still persist. This is particularly so among underprivileged populations in both developing and developed countries. Poor oral health may have a profound influence on general health, and several oral diseases such as periodontal disease and dental caries have historically been considered the most important global oral health burdens. Dental caries is still the most prevalent disease even in most

\author{
Corresponding author: \\ Charles Mugisha Rwenyonyi, \\ Department of Dentistry \\ College of Health Sciences \\ Makerere University \\ P.O.Box 7072 \\ Kampala \\ E-mail: mrwenyonyi@chs.mak.ac.ug \\ Tel. 25677405349
}

industrialized countries as it affects up to $100 \%$ of both school going children and adults ${ }^{2}$. WHO ${ }^{3}$ recommends that there should be regular national oral health surveys at least every 10 years for planning purposes. In a previous pilot survey ${ }^{4}$ on oral conditions in Uganda, it was revealed that the severity of dental caries was low although the disease was widespread with most carious teeth untreated. Dental caries is a lifestyle disease, preventable through policy formulation and strategic planning ${ }^{2}$. However, in Uganda, there are no up to date caries data on which to base policy formulation and strategic planning. This was echoed by the Uganda $\mathrm{Na}-$ tional Health Policy and Strategic Plan for 2011 -2015, which clearly stated that a National Oral Health Survey was overdue, as the last one was conducted almost 3 decades ago ${ }^{5}$. The aim of the present study was to establish the prevalence and factors associated with dental caries among adults and children in seven districts of Uganda.

\section{Materials and methods Study design}

This was a cross sectional study using a multi-stage sampling technique in seven districts of Uganda. 


\section{Study setting}

Primary schools in the districts of Gulu, Soroti, Jinja, Masaka, Kabale, Kabarole and Hoima were used as study areas for children aged 11-13 years. A list of primary schools in the district was obtained from the respective District Education Officers and two schools; 1 urban and 1 rural, were randomly selected in each district by casting lots, totaling 14 schools in the 7 districts. On average, each primary school has 500 children. For the adults a list of all parishes in a district was obtained from the district chief administrative office. Six parishes ( 3 urban and 3 rural) were randomly selected by casting lots. One Local Council (LC) I or village in each parish was also similarly randomly selected totaling 42 local councils in the seven districts. An LCI has a population of about 300 people.

\section{Selection of subjects}

Two age categories were considered for the field survey that is $11-13$ (average 12) year age group for children and 35-44 age group for adults, which are recommended by $\mathrm{WHO}^{3}$. Identifying the age of a child was based on school registers and confirmed by the children themselves. All the children whose age fell within a range of 11 and 13 years were requested to make two lines according to gender. Using random numbers, a total of 1230 children were selected for the study. The adult participants were selected by a convenience method due to the difficulties in establishing their actual age from records and mobilizing them in specific examination centers. The LC I officials were requested to mobilize adults in their homesteads. Taking the residence of the LC I Chairperson of the selected area as the focal point, the examiners moved from household to household examining adults whose age fell within 35-44 years, totaling 648 participants.

\section{Calibration of examiners}

Before the field survey, 4 trained dentists (LMM, CMR, $\mathrm{AK}$, and $\mathrm{EMN}$ ) were calibrated in oral examination among the 12 year olds $(n=20)$ in St. Martin Primary School, Kampala, in order to minimize inter-examiner variability. The mean inter-examiner agreement in recording caries was aimed at Cohen's kappa value of at least 0.8 .

\section{Clinical examination}

Intra-oral examination of the participants was carried out by 4 trained and calibrated dentists under field conditions. Two dentists worked as a pair: one as an examiner and the other as an assistant. An assistant recorded the observations as dictated by the examiner. To avoid fatigue, they changed their roles after examining every 10 participants. The participant was examined while lying on a portable couch in a supine position in a shade. Indirect sunlight was the source of illumination. A disposable mouth mirror and dental probe were used for the intraoral examination.

Caries was assessed using Decayed Missing Filled Teeth (DMFT) index ${ }^{6}$ according to criteria described by $\mathrm{WHO}^{3}$. Caries was recorded as being present when a lesion in a pit/fissure or on a smooth surface had a detectable softened floor, undermined enamel, softened wall or temporary filling. On proximal surfaces, the probe had to enter the lesion with certainty. When in doubt, the carious lesion was not recorded. Stained pits or fissures that caught the probe, but did not have undermined enamel, softened floor or walls were not included as carious lesions. A tooth was considered filled if it had a permanent restoration and it was considered missing due to caries if there was history of pain and or presence of a cavity prior to extraction.

\section{Background information}

A short structured questionnaire was administered to the participants in form of an oral interview in order to obtain demographic information, oral hygiene practices, and dietary habits in accordance with the World Health Organization recommended form ${ }^{3}$.

\section{Reliability test}

Separate examination for dental caries in about $10 \%$ of the children in each of the 7 districts a few days after the main examination for reliability test gave a substantial agreement. Cohen's kappa values ranged from 0.80 to 0.84 and 0.79 to 0.83 , respectively, with no evidence of systematic error in both examiners ( $p>0.05$, Wilcoxon test).

\section{Informed consent}

The study followed a protocol as approved by Makerere University, School of Medicine Institutional Review Board as well as Uganda National Council of Science and Technology (Reference no. MV 692). Permission to carry out the study was granted by the respective local district and school authorities. The participants gave informed consent. Since there were no invasive procedures, the head teachers gave consent on behalf of the children. The children also assented before they participated in the study. The nature of the study and the 
participants' right to accept or refuse to take part in the study were dully explained to the participants in accordance with Helsinki Declaration?

\section{Statistical analyses}

The data was analysed using the Statistical Package for Social Sciences, version 17 for windows, Chicago IL, USA. Cohen's kappa coefficient was used to assess inter- and intra-examiner agreements. Wilcoxon SignedRanks test for paired observations was used to check for intra-examiner systematic errors in recording caries. Student's t test for independent samples was used to assess any significant differences between means of quantitative variables. Chi-square $(\chi 2)$ statistics were used to compare frequency distributions of participants on the basis of prevalence of dental caries, gender, age, area of residence and other variables. The level of significance was set at $5 \%$.

\section{Results}

A total of 1,878 study participants were recruited in the survey (Table 1). This comprised 1,230 (65.5\%) school children and 648 (34.5\%) adults, the majority of whom were from low socio-economic background. Except in
Hoima and Soroti districts, most of the participants were rural residents (Table 1). Kabarole and Masaka districts had the least number of participants in the urban areas. More females (60.4\%) participated in the survey although the difference within the districts was not statistically significant.

The severity of dental caries was generally low. The overall mean DMFT score for children was 0.73 and for adults, 4.71 (Table 1). Generally, there was a higher mean DMFT score in the rural areas (2.19) as compared to urban (1.97) (Table 1). In all the districts, except Hoima, there was a tendency to a higher mean DMFT score of children in rural as compared to urban (Table 1). A similar trend was seen in adults although less marked. There was a significant difference in the mean DMFT score of adults between the urban and rural areas in Masaka, Hoima and Gulu districts $(\mathrm{p}<0.05)$.

The prevalence of dental caries was higher in adults $(66.7 \%)$ as compared to children (32.5\%, Table1). The highest prevalence of dental caries in adults was recorded in Hoima district while the lowest was in Gulu: $90.1 \%$ versus $48.8 \%$. The corresponding values in children were seen in Masaka and Kabarole districts, 45.0\% and $21.3 \%$, respectively (Table 1 ).

Table 1: The frequency distribution of participants according to age, place of residence in district, the mean Decayed, Missing and Filled teeth (DMFT) score and caries prevalence $(n=1878)$

\begin{tabular}{|c|c|c|c|c|c|c|c|}
\hline District & Residence & $\begin{array}{l}\text { No. of } \\
\text { children } \\
\text { n }(\%) \\
\end{array}$ & $\begin{array}{l}\text { No. of } \\
\text { adults } \\
\text { n }(\%)\end{array}$ & $\begin{array}{l}\text { DMFT } \\
\text { scores } \\
\text { Child } \\
\end{array}$ & $\begin{array}{l}\text { DMFT } \\
\text { scores } \\
\text { Adults } \\
\end{array}$ & $\begin{array}{l}\text { Caries } \\
\text { prevalence } \\
\text { children }(\%)\end{array}$ & $\begin{array}{l}\text { Caries } \\
\text { prevalence } \\
\text { Adults (\%) } \\
\end{array}$ \\
\hline \multirow[t]{2}{*}{ Kabale } & Urban & $33(44.6)$ & $\begin{array}{l}41 \\
(55.4)\end{array}$ & 0.39 & 4.15 & \multirow[t]{2}{*}{25.3} & \multirow[t]{2}{*}{79.2} \\
\hline & Rural & $\begin{array}{l}153 \\
(64.6)\end{array}$ & $\begin{array}{l}84 \\
(35.4)\end{array}$ & 0.53 & 5.71 & & \\
\hline \multirow[t]{2}{*}{ Masaka } & Urban & $40(80.0)$ & $\begin{array}{l}10 \\
(20.0)\end{array}$ & 0.93 & 6.00 & \multirow[t]{2}{*}{45.0} & \multirow[t]{2}{*}{85.9} \\
\hline & Rural & $89(62.2)$ & $\begin{array}{l}54 \\
(37.8)\end{array}$ & 1.00 & 8.59 & & \\
\hline \multirow[t]{2}{*}{ Hoima } & Urban & $90(54.9)$ & $\begin{array}{l}74 \\
(45.1)\end{array}$ & 0.94 & 6.89 & \multirow[t]{2}{*}{41.8} & \multirow[t]{2}{*}{90.1} \\
\hline & Rural & $91(61.5)$ & $\begin{array}{l}57 \\
(38.1)\end{array}$ & 0.80 & 4.39 & & \\
\hline \multirow[t]{2}{*}{ Kabarole } & Urban & $92(92.9)$ & $7(7.1)$ & 0.36 & 3.43 & \multirow[t]{2}{*}{21.3} & \multirow[t]{2}{*}{59.5} \\
\hline & Rural & $90(75.0)$ & $\begin{array}{l}30 \\
(25.0)\end{array}$ & 0.42 & 1.53 & & \\
\hline \multirow[t]{2}{*}{ Gulu } & Urban & $75(81.5)$ & $\begin{array}{l}17 \\
(18.5) \\
\end{array}$ & 0.61 & 0.24 & \multirow[t]{2}{*}{27.1} & \multirow[t]{2}{*}{48.8} \\
\hline & Rural & $\begin{array}{l}113 \\
(62.1) \\
\end{array}$ & $\begin{array}{l}69 \\
(37.9)\end{array}$ & 0.73 & 3.55 & & \\
\hline \multirow[t]{2}{*}{ Soroti } & Urban & $\begin{array}{l}113 \\
(76.4)\end{array}$ & $\begin{array}{l}35 \\
(23.6)\end{array}$ & 1.21 & 3.46 & \multirow[t]{2}{*}{36.9} & \multirow[t]{2}{*}{65.2} \\
\hline & Rural & $63(64.9)$ & $\begin{array}{l}34 \\
(35.1)\end{array}$ & 0.75 & 4.76 & & \\
\hline \multirow[t]{2}{*}{ Jinja } & Urban & $63(64.9)$ & $\begin{array}{l}34 \\
(35.1)\end{array}$ & 0.60 & 4.38 & \multirow[t]{2}{*}{30.1} & \multirow[t]{2}{*}{77.9} \\
\hline & Rural & $\begin{array}{l}123 \\
(54.7)\end{array}$ & $\begin{array}{l}102 \\
(45.3)\end{array}$ & 0.77 & 3.56 & & \\
\hline
\end{tabular}


The majority of participants $(79.9 \% \mathrm{n}=1309)$ reported to frequently eat sugared snacks especially cakes (30.4\%) and biscuits (23.7\%). About $65 \%$ of the participants were taking sugared drinks four times a week. Overall, 95\% $(n=1788)$ of the participants cleaned their teeth. The highest prevalence $(98.2 \%)$ of tooth cleaning was recorded in Jinja district and the lowest (87.5\%) in Kabale (Table 2). The majority of the participants
$(85.8 \%, \mathrm{n}=1541)$ brushed their teeth once or twice daily in almost equal proportions (Table 2). All adults in Masaka and children in urban Jinja district cleaned their teeth either once or twice daily (Table 2). About 71.7\% of the subjects were cleaning their teeth with plastic tooth brushes while chewing stick was reportedly used by $28.3 \%$ of the participants, particularly children in rural communities in Kabale and Soroti districts and rural adults in Soroti district (Table 2).

Table 2: The frequency distribution of subjects according to district and place of residence, age group, frequency of tooth cleaning and type of cleaning devise used

\begin{tabular}{|c|c|c|c|c|c|c|c|c|c|}
\hline \multirow[t]{2}{*}{ District } & \multirow{2}{*}{$\begin{array}{l}\text { Reside } \\
\text { nce }\end{array}$} & \multirow{2}{*}{$\begin{array}{l}\text { Age } \\
\text { category }\end{array}$} & \multirow{2}{*}{$\begin{array}{l}\text { Positive } \\
\text { response to } \\
\text { tooth } \\
\text { brushing } \mathrm{n} \\
\text { (\%) }\end{array}$} & \multicolumn{3}{|c|}{ Frequency of tooth cleaning $(n=1792)$} & \multicolumn{3}{|c|}{ Type of device $(n=1765)$} \\
\hline & & & & $\begin{array}{ll}\text { Once } & \text { a } \\
\text { day } & \\
\text { n (\%) } & \end{array}$ & $\begin{array}{ll}\text { Twice } & \text { a } \\
\text { day } & \\
\text { n (\%) } & \end{array}$ & $\begin{array}{l}\text { Occasion } \\
\text { al } \\
\text { n (\%) }\end{array}$ & $\begin{array}{l}\text { Plastic } \\
\text { tooth } \\
\text { brush } \\
\text { n }(\%)\end{array}$ & $\begin{array}{l}\text { Chewing } \\
\text { stick } \\
\text { n (\%) }\end{array}$ & $\begin{array}{l}\text { Others } \\
\text { n (\%) }\end{array}$ \\
\hline \multirow[t]{4}{*}{ Kabale } & \multirow[t]{2}{*}{ Urban } & Children & $274(87.5)$ & $14(51.9)$ & $2(7.4)$ & $11(40.7)$ & $12(44.4)$ & $14(51.9)$ & $1(3.7)$ \\
\hline & & Adult & $39(12.5)$ & $16(40.0)$ & $21(52.5)$ & $2(5.0)$ & $31(79.5)$ & $8(20.5)$ & $0(0.0)$ \\
\hline & \multirow[t]{2}{*}{ Rural } & Children & 178 (92.2) & $45(33.1)$ & $34(25.0)$ & $57(41.9)$ & $30(22.1)$ & $96(70.6)$ & $10(7.3)$ \\
\hline & & Adult & $15(7.8)$ & $27(38.0)$ & $9(12.7)$ & $35(49.3)$ & $39(55.7)$ & $31(44.3)$ & $0(0.0)$ \\
\hline \multirow[t]{4}{*}{ Masaka } & \multirow[t]{2}{*}{ Urban } & Children & $306(97.8)$ & $20(52.6)$ & $11(28.9)$ & $7(18.4)$ & $32(84.2)$ & $6(15.8)$ & $0(0.0)$ \\
\hline & & Adult & $7(2.2)$ & $4(36.4)$ & $7(63.6)$ & $0(0.0)$ & $10(100)$ & $0(0.0)$ & $0(0.0)$ \\
\hline & \multirow[t]{2}{*}{ Rural } & Children & $215(95.1)$ & $37(46.3)$ & $30(37.5)$ & $13(16.3)$ & $47(58.7)$ & $31(38.8)$ & $2(2.5)$ \\
\hline & & Adult & $11(4.9)$ & $24(48.0)$ & $26(52.0)$ & $0(0.0)$ & $32(64.0)$ & $18(36.0)$ & $0(0.0)$ \\
\hline \multirow[t]{4}{*}{ Hoima } & \multirow[t]{2}{*}{ Urban } & Children & $269(98.2)$ & $40(46.0)$ & $43(49.4)$ & $4(4.6)$ & $78(88.6)$ & $10(11.4)$ & $0(0.0)$ \\
\hline & & Adult & $5(1.8)$ & $30(40.5)$ & $42(56.8)$ & $2(2.7)$ & $66(89.2)$ & $8(10.8)$ & $0(0.0)$ \\
\hline & \multirow[t]{2}{*}{ Rural } & Children & 237 (96.7) & $45(51.1)$ & $41(46.6)$ & $2(2.3)$ & $53(60.2)$ & $35(39.8)$ & $0(0.0)$ \\
\hline & & Adult & $81(3.3)$ & $22(39.3)$ & $29(51.8)$ & $5(8.9)$ & $46(82.1)$ & $9(16.1)$ & $1(1.8)$ \\
\hline \multirow[t]{4}{*}{ Kabarole } & \multirow[t]{2}{*}{ Urban } & Children & $316(98.1)$ & $36(40.9)$ & $37(42.0)$ & $15(17.1)$ & $55(62.5)$ & $28(31.8)$ & $5(5.7)$ \\
\hline & & Adult & $6(1.9)$ & $5(71.4)$ & $1(14.3)$ & $1(14.3)$ & $5(71.4)$ & $2(28.6)$ & $0(0.0)$ \\
\hline & \multirow[t]{2}{*}{ Rural } & children & $274(87.5)$ & $34(37.8)$ & $43(47.8)$ & $13(14$. & $59(83.1)$ & $2(2.8)$ & $10(14.1)$ \\
\hline & & Adult & $39(12.5)$ & $15(50.0)$ & $12(40.0)$ & $3(10.0)$ & $20(66.7)$ & $9(30.0)$ & $1(3.3)$ \\
\hline \multirow[t]{4}{*}{ Gulu } & \multirow[t]{2}{*}{ Urban } & Children & $178(92.2)$ & $28(37.8)$ & $31(41.9)$ & $15(20.3)$ & $66(89.2)$ & $8(10.8)$ & $0(0.0)$ \\
\hline & & Adult & $15(7.8)$ & $4(23.5)$ & $12(70.6)$ & $1(5.9)$ & $15(88.2)$ & $2(11.8)$ & $0(0.0)$ \\
\hline & \multirow[t]{2}{*}{ Rural } & Children & $306(97.8)$ & $29(26.1)$ & $58(52.3)$ & $24(21.6)$ & $92(82.9)$ & $19(17.1)$ & $0(0.0)$ \\
\hline & & Adult & $7(2.2)$ & $26(39.4)$ & $30(45.4)$ & $10(15.2)$ & $52(77.6)$ & $15(22.4)$ & $0(0.0)$ \\
\hline \multirow[t]{4}{*}{ Soroti } & \multirow[t]{2}{*}{ Urban } & Children & $215(95.1)$ & $48(44.0)$ & $52(47.7)$ & $9(8.3)$ & $99(90.8)$ & $10(9.2)$ & $0(0.0)$ \\
\hline & & Adult & $11(4.9)$ & $19(54.3)$ & $14(40.0)$ & $2(5.7)$ & $24(68.6)$ & $11(31.4)$ & $0(0.0)$ \\
\hline & \multirow[t]{2}{*}{ Rural } & Children & $269(98.2)$ & $40(64.5)$ & $18(29.0)$ & $4(6.5)$ & $14(22.6)$ & $48(77.4)$ & $0(0.0)$ \\
\hline & & Adult & $5(1.8)$ & $17(54.8)$ & $11(35.5)$ & $3(9.7)$ & $11(35.5)$ & $20(64.5)$ & $0(0.0)$ \\
\hline \multirow[t]{4}{*}{ Jinja } & \multirow[t]{2}{*}{ Urban } & Children & $237(96.7)$ & $43(68.3)$ & $20(31.7)$ & $0(0.0)$ & $59(93.7)$ & $4(6.3)$ & $0(0.0)$ \\
\hline & & Adult & $81(3.3)$ & $18(52.9)$ & $12(35.3)$ & $4(11.8)$ & $32(94.1)$ & $2(5.9)$ & $0(0.0)$ \\
\hline & \multirow[t]{2}{*}{ Rural } & Children & $316(98.1)$ & $70(59.8)$ & 42 (35.9) & $5(4.3)$ & $93(79.5)$ & $24(20.5)$ & $0(0.0)$ \\
\hline & & Adult & $6(1.9)$ & $43(42.6)$ & $54(53.5)$ & $4(3.9)$ & $90(88.2)$ & $12(11.8)$ & $0(0.0)$ \\
\hline Total & & & 1788 (95.2) & 799 (44.6) & 742 (41.4) & 251(14.0) & $1262(71.7)$ & $482(28.3)$ & $21(1.2)$ \\
\hline
\end{tabular}

Other devices included: sand, charcoal, plant leaves

\section{Discussion}

The present study was part of the survey to collect data on oral health status in seven districts closely representing all the geographical regions of Uganda. It was thus assumed that to a great extent the data collected in the present study would give a national dental caries status of the population. Two of the index age groups: 12 years representing the children and the 35-44 years representing adults previously recommended in oral health surveys $^{3}$ were used in the present study. Different age 
groups are reported to show significantly different patterns of oral health status because of variable demographic factors.

Coincidentally, about two-thirds of the participants were from the rural areas of most districts in support of the fact that majority of Ugandan communities reside in the rural $\operatorname{areas}^{8}$ thus, a proportional representation in the present study.

The overall mean DMFT score was 0.73 for children (Table 1), which is comparable to previous reports in Uganda $^{4}$ and Burkina Faso ${ }^{9}$, but much lower than 3.0 set as the global goal by the year 2015 for children aged 12 years $^{10}$. On the other hand, the mean DMFT score for adults was 4.71 , which is higher than 3.4 previously observed in a Ugandan population ${ }^{4}$, but lower than 6.3 reported in Burkina Faso9. The overall caries prevalence was $32.5 \%$ in children and $66.7 \%$ in adults (Table 1), which is comparable to other previous studies in Uganda ${ }^{11,12}$. This is an indication of wide spread disease in an epidemic proportion among the population $^{3}$. This may be due to inadequacy of resources such as oral health personnel and dental facilities as well as lack of awareness about oral health and dental services among the majority of the population as found in other African countries ${ }^{13-15}$. We also found dental caries to increase with age, a finding that corroborates previous studies in Uganda ${ }^{4,11,12}$. This supports the view that the younger age groups should be a focus for preventive programmes ${ }^{16}$.

In the present study, $95.2 \%$ of the participants indicated that they cleaned their teeth (Table 2). It was also impressive to note that $94.4 \%$ of the rural participants reported to regularly brush their teeth (Table 2). Tooth brushing especially with fluoride toothpaste is well known remedy to development of dental caries ${ }^{2}$. A good proportion $(71.7 \%)$ of the participants used toothbrushes while $27.3 \%$ used chewing sticks (Table 2). This is consistent with findings in the previous study among 10-14 year old rural Ugandans ${ }^{11}$. Although majority of the participants cleaned their teeth and on a regular basis, the benefits may be counteracted by high consumption of sugar. About $80 \%$ of the participants reported occasional consumption of sugared snacks and drinks which is a cause for concern. Oral health education against frequent consumption of sugared snacks and drinks is an absolute necessity.

\section{Conclusion}

In as much as the severity of dental caries was low, the disease was widespread in the study population. Although majority of the population brushed their teeth and at regular basis, a high proportion reported consumption of sugared snacks and drinks, which calls for oral health education to increase the awareness of the dangers of high frequency of sugar consumption.

\section{Acknowledgements}

The authors are grateful to the School of Medicine Institutional Review Board and Uganda National Council for Science and Technology for the ethical approval to carry out this study. We are grateful to the participants who took part in the study. The school teachers and LC I officials were instrumental in mobilizing the participants. The Rockfeler Foundation through i@Mak financially supported the study. The MEPI-MESAU facilitated the manuscript writing.

\section{References}

1. Petersen PE. The World Oral Health Report 2003: continuous improvement of oral health in the 21st century - the approach of the WHO Global Oral Health Programme. Community Denti Oral Epidemiol. 2003;31(Suppl 1):3-24.

2. Bagramian RA, Garcia-Godoy F, Volpe AR. The global increase in dental caries. A pending public health crisis. Am J Dent. 2009;22:3-8.

3. World Health Organization. Oral health surveys. Basic methods. 5th ed. Geneva, 1997.

4. Muwazi LM, Rwenyonyi CM, Tirwomwe FJ, Ssali C, Kasangaki A, Nkamba ME, Ekwaru P. Prevalence of oral diseases/conditions in Uganda. Afri Health Sci. 2005; 5(3):227 - 233

5. Tirwomwe JF, Ekoku Y, Manji F, Fejerskov O. Uganda National Oral Health Survey 1987, Ministry of Health, Uganda/Kenya Medical Research Institute. 1988.

6. Klein H, Palmer CE, Knutson FW. Studies on dental caries I. Dental status and dental needs of elementary school children. Public Health Report. 1938;53:751765.

7. Krleža-Jerić K, Lemmens T: 7th Revision of the Declaration of Helsinki: Good News for the Transparency of Clinical Trials. Croatian Med J. 2009, 50(2): 105-110. 8. Uganda Beaural of statistics. The state of Uganda population report. The population and social transformation: addressing the needs of special interest groups, 2013.

9. Varenne B, Petersen PE, Ouattara S Oral health status of children and adults in urban and rural areas of Burkina Faso, Africa. Int Dent J. 2004; 54: 83-89 
10. Bratthall D. Introducing the Significant Caries Index together with a proposal for a new global oral health goal for 12-year-olds. Int Dent J. 2000; 50, 378-384 11. Rwenyonyi CM, Birkeland JM, Haugejorden O, Bjorvatn $\mathrm{K}$. Dental caries among 10- to 14-year-old children in Ugandan rural areas with 0.5 and $2.5 \mathrm{mg}$ fluoride per liter in drinking water. Clin Oral Invest. 2001;5(1):45-50. 12. Rwenyonyi CM, Muwazi LM, Buwembo W. Assessment of factors associated with dental caries in rural communities in Rakai District, Uganda. Clin Oral Invest. 2011;15(1):75-80.
13. Bajomo AS, Rudolph MJ, Ogunbodede EO. Dental caries in 6,12 and 15 year old Venda children in South Africa. East Afri Med J. 2004; 81(5): 236-243

14. Monastir AA. Oral health in Tunisia. Int Dent J. 2004; 54: 389-394

15. Philippus J, van Wyk PJ, van Wyk C. Oral health in South Africa. Int Dental J. 2004: 54; 373-377

16. Gugushe TS, du Plessis JB, Regional urban-rural distribution of dental caries in Swaziland. J. Dent. Assoc. South Afri. 1998; 53:409-412. 